\title{
KONSEP, POLA, DAN IDEOLOGI KETOPRAK TJONTHONG
}

\author{
Retno Dwi Intarti \\ Institut Seni Indonesia Yogyakarta, Indonesia \\ intarti_retno2@yahoo.com
}

\begin{abstract}
Abstrak: Penelitian ini bertujuan untuk menjelaskan humor dalam Ketoprak Tjonthong yang meliputi konsep, pola, dan ideologinya. Ketoprak Tjonthong merupakan grup ketoprak yang dibentuk di Yogyakarta tahun 2004 dan telah berhasil mementaskan sebanyak 33 lakon dimulai dari Lakon Minggat (2004) sampai dengan Lakon Walidarma (2019). Objek kajian penelitian ini adalah lakon Panguwasa Samodra (2019). Di samping dua lakon lain yang diamati untuk membantu analisis yaitu lakon Baron Sakendher dan lakon Keris Mataram. Adapun analisis tentang konsep humor, pola dan ideologinya akan digunakan teori humor dari Arthur Berger dan kajian struktural. Langkah penelitian yang dilakukan terdiri dari dua tahap, yaitu tahap pengumpulan data dan tahap analisis data. Data dikumpulkan dengan melakukan studi pustaka dan bedah naskah. Sedangkan tahap analisis data dilakukan dengan melacak peristiw a yang terjadi, klasifikasi data, untuk menemukan konsep humor, pola, dan ideologi Ketoprak Tjonthong. Hasilnya ditemukan sekitar 16 konsep humor lakon Panguwasa Samodra, di antaranya adalah bombast, irony, misunderstanding, pun, repartee, sarcasm, sexual allusion, conceptual surprise, absurd, repetition, ignorance, embarrassment, imitation, clumsiness, chase, dan exaggeration. Selain itu, terdapat tiga pola humor dalam Ketoprak Tjonthong yaitu pola pengkarakteran pemain, pola penamaan tokoh, dan pola pengadegan. Berkaitan dengan ideologi, terdapat tiga hal yang menjadi ciri khas Ketoprak Tjonthong dan selalu menjadi konsep dasar pementasannya yaitu menggarap fenomena sosial masyarakat, mengangkat cerita-cerita baru dalam khasanah ketoprak, dan menggunakan humor satir sebagai presentasi estetisnya.
\end{abstract}

Kata kunci: Ketoprak Tjonthong, konsep humor, pola humor, ideologi

\begin{abstract}
This study aims to explain the humour in Ketoprak Tjonthong, which includes its concepts, patterns, and ideology. Ketoprak Tjonthong is a ketoprak group formed in Yogyakarta in 2004 and has successfully performed 33 plays starting from Lakon Minggat (2004) to Lakon Walidarma (2019). The object of this research study is the play Panguwasa Samodra (2019). In addition to the two other plays that were observed to assist the analysis, they were the Baron Sakendher play, and the Keris Mataram play. As for the analysis of the concept of humour, its patterns and ideology, the theory of humour from Arthur Berger and structural studies will be used. The research step consisted of two stages, namely the data collection stage and the data analysis stage. Data were collected by conducting literature studies and text review. In comparison, the data analysis stage was carried out by tracking the events that occurred, classifying the data, to find the humorous concept, patterns, and ideology of Ketoprak Tjonthong. The results found around 16 humorous concepts for the Panguw as a Samodra play, including bombast, irony, misunderstanding, pun, repartee, sarcasm, sexual allusion, conceptual surprise, absurd, repetition, ignorance, embarrassment, imitation, clumsiness, chase, and exaggeration. In addition, there are three humour patterns in Ketoprak Tjonthong, namely the character pattern, the character naming pattern, and the scene pattern. Regarding ideology, three things characterize Ketoprak Tjonthong and have always been the basic concept of its
\end{abstract}


performances, namely working on social phenomena in society, lifting new stories in the ketoprak realm, and using satirical humour as its aesthetic presentation.

Keywords: Ketoprak Tjonthong, the concept of humour, humour patterns, ideology

\section{Pendahuluan}

Ketoprak Ringkes Tjap Tjonthong yang selanjutnya akan disebut Ketoprak Tjonthong lahir di Yogyakarta tahun 2004. Keterlibatan beberapa seniman ketoprak tradisi yaitu Susilo Nugroho, Marwoto, Nano Asmorodono, dan Kocil Birowo (Maulana, 2016) yang membidani lahirnya Ketoprak Tjonthong, membuat grup ini tumbuh berkembang dan dikenal oleh masyarakat. Produktifitas grup ini dalam pementasan ketoprak tak perlu diragukan lagi. Hingga saat ini, Ketoprak Tjonthong telah berhasil mementaskan sebanyak 33 lakon dimulai dari lakon Minggat (2004) sampai dengan lakon Walidarma (2019) yang berupa pertunjukan langsung (live). Di masa pandemi ini, Ketoprak Tjonthong telah melakukan pertunjukan daring sebanyak 2 kali yaitu tanggal 17 Oktober 2020 dengan lakon Keris Mataram dan 18 November 2020 dengan lakon Walidarma. Pementasan ini dilakukan dalam rangka Pertunjukan Virtual Kesenian Tradisional yang diinisiasi oleh Komite Penanganan Covid-19 dan Pemulihan Ekonomi Nasional (KPC PEN) didukung oleh Kominfo. Ketoprak Tjonthong memiliki keunikan yang membedakan grup ini dari grup ketoprak lainnya. Keunikannya yakni unsur humor yang seakan mendominasi bangunan alur cerita dan suasana pementasan. Dari semua pementasan yang pernah dilakukan, Ketoprak Tjonthong selalu menyampaikan persoalan kehidupan yang terjadi dalam masyarakat menggunakan balutan humor.

Cara penyampaian yang tidak spaneng, menggunakan bahasa yang lugas dan cerdas, penyajian yang santai tapi serius, mampu membuat penonton tertohok tapi tidak marah adalah ciri khusus dari grup Ketoprak Tjonthong (Intarti, 2020, p. 2). Dengan ciri khas tersebut, grup ini tetap eksis dan memiliki banyak penggemar.

Biasanya, adegan humor dalam ketoprak konvensional muncul bersamaan dengan kehadiran abdi keputren atau kasatrian yang diperankan oleh pemain dagelan/lawak. Adegan dagelan menjadi salah satu adegan yang dinanti kemunculannya karena mampu memberikan suasana berbeda sehingga penonton tak merasa bosan. Unsur humor menjadi magnet yang mampu membuat penonton tetap bertahan hingga pertunjukan usai digelar. Dengan demikian, dalam pertunjukan ketoprak, unsur humor sangat penting untuk dihadirkan. Unsur humor dalam ketoprak yang semula terbatas hanya dilakukan oleh tokoh tertentu (dagelan/emban), dalam perkembangannya bisa dilakukan oleh tokoh siapa saja dan kapan saja. Dengan berbagai kelucuan yang disajikan seperti lelucon kata, slapstikcs, dan perkelahian segar, ketoprak menjadi seni pertunjukan yang rame tur kathah luconipun (Soemanto, 1997, p. 126). Bukannya tanpa alasan jika ketoprak masa kini dituntut lebih banyak action. Action tidak hanya canggih, mendebarkan, dan mengundang tepuk tangan, tetapi juga harus menggelitik dawai hati agar bisa hua ha ha ha. Perkelahian bukan model perang IrakIran yang penuh dengki-dendam, dan keji, tetapi tetap lucu dan menghibur. Darah tak perlu mengalir, mayat tak perlu bergelimpangan sebab yang berkelahi adalah pelawak (Soemanto, 1997, p. 129-130).

Ketoprak Tjonthong menggunakan idiom humor dalam porsi banyak di setiap pertunjukannya. Hal ini menarik untuk dikaji 
lebih lanjut terkait konsep humor, pola humor, dan ideologi yang mendasari pemilihan tersebut. Tulisan ini akan membahas hal tersebut dengan mengkaji salah satu lakon yang pernah dipentaskan tahun 2019 berjudul Panguwasa Samodra. Untuk menambah kelengkapan kajian akan diamati juga dua lakon yang lain yakni Baron Sakendher dan Keris Mataram.

\section{Penelitian Sebelumnya}

Tulisan tentang Ketoprak telah terbit dalam bentuk buku maupun jurnal. Beberapa tulisan dalam bentuk buku di antaranya yakni Wijaya dan F.A. Sutjipto dalam bukunya berjudul Ketoprak Teater Rakyat Jawa Tengah dan Daerah Istimewa Yogyakarta (1977), Handung Kusudyarsana dalam bukunya Ketoprak (1989), Judith E. Bosnak (2006) dalam bukunya Shaping The Javanese Play: Improvisation of the Script in Theater Performance, serta Lephen Purwarahardja dan Bondan Nusantara dalam bukunya berjudul Ketoprak Orde Baru (1997). Dua tulisan lain juga mengupas ketoprak dalam konteks masa kini menggunakan kajian post kolonial, yaitu The Politics of the Past in the Present Day Java (Kanisius, 1997) dan Imajinasi Penguasa dan Identitas Post Kolonial: Siasat Politik (Kethoprak) Massa Rakyat (Kanisius, 1999) karya Budi Susanto S.J.

Tulisan di jurnal yang membahas tentang ketoprak yakni tulisan Bagus Wahyu Setyawan dan Kundharu Saddhono yang dimuat di jurnal Dance \& Theater Review (2019) berjudul "Akulturasi budaya IslamJawa dalam Pementasan Kesenian Ketoprak". Tulisan tersebut menjelaskan bahwa ketoprak gaya mesiran merupakan hasil akulturasi Islam dan Jawa. Ketoprak gaya ini mampu memberi nuansa baru pada ketoprak. Nuansa hadir berkat adanya adaptasi berbagai unsur seperti cerita, bahasa, kostum, make up, dan iringan. Tulisan lain yang juga membahas tentang ketoprak berjudul "Strategi Penguatan Kreativitas Seniman Ketoprak DIY tahun 1999 hingga tahun 2009" (Yudiaryani, Nurcahyono, \& Purba, 2019). Isi tulisan menjelaskan bahwa selama dasa warsa terakhir ketoprak telah berhasil menjadi ikon budaya dan pariwisata di DIY. Hal ini tidak terlepas dari kesadaran pemerintah, seniman, kesadaran strategi tata ruang artistik, pengaruh humor ketoprak, dan cerita menembus ranah seni yang lain dan kontekstual dengan masa kini.

Kegiatan penelitian yang pernah dilakukan penulis dengan objek material ketoprak adalah Skripsi S-1 (1997) dengan judul "Gaya Akting Ketoprak Mataram (Studi Kasus Grup Ketoprak PS Bayu)." Tahun 2006 dilakukan penelitian berjudul "Perempuan dalam Naskah Ketoprak Handung Kusudyarsana." Selanjutnya pada tahun 2008, dilakukan penelitian berjudul "Bentuk Pementasan Ketoprak Mataram RRI Nusantara II Yogyakarta." Tahun 2010 dilakukan penelitian dengan judul "Ketoprak RRI Nusantara II Yogyakarta Pengemban Keberlangsungan Teater Tradisi di Yogyakarta "(Tesis S-2).

Tulisan penting lain berkaitan dengan objek material Ketoprak Tjonthong berupa skripsi karya Alif Maulana mahasiswa Jurusan Teater ISI Yogyakarta dengan judul Kethoprak Conthong Yogyakarta dalam Lakon Lampor Kajian Bentuk dan Fungsi Pertunjukan. Dalam tulisannya, Maulana membahas bentuk pertunjukan Ketoprak Tjonthong yang dianalisis memakai teori struktur dan tekstur (Kernodle) dan fungsi seni pertunjukan menggunakan teori semiotika teater (Nur Sahid). Adapun pertunjukan yang diamati adalah pementasan Ketoprak Tjonthong dalam lakon Lampor.

Berdasarkan beberapa tulisan di atas, belum banyak tulisan yang membahas tentang Ketoprak Tjonthong secara komprehensif. Kalaupun ada yang sudah menulis, baru membahas struktur dan fungsi pertunjukan Ketoprak Tjonthong belum 
menyentuh ranah konsep humor, pola dan ideologinya sehingga kajian ini perlu dilakukan.

\section{LandasanTeori}

Berkaitan landasan teori akan disampaikan konsep humor yang digunakan dalam tulisan ini. Terdapat beberapa definisi tentang humor. Secara garis besar definisi humor itu adalah rasa atau gejala yang merangsang kita untuk tertawa atau cenderung tertawa secara mental, ia bisa berupa rasa atau kesadaran di dalam diri kita (sense of humor); dan bisa berupa suatu gejala atau hasil cipta dari dalam maupun dari luar diri kita. Bila dihadapkan pada humor, kita bisa langsung tertawa lepas atau cenderung tertawa saja; misalnya tersenyum atau merasa tergelitik di dalam batin saja. Rangsangan yang ditimbulkan haruslah rangsangan mental untuk tertawa, bukan rangsangan fisik seperti dikili-kili yang mendatangkan rasa geli namun bukan akibat humor (Setiawan dalam Rahmanadji, 2007: 216).

Teori humor dari Arthur Berger yang disarikan oleh Anastasya menjadi empat kategori dasar humor yaitu: language/ the humor is verbal, the humor is ideational, Identity/ the humor is existensial dan Action/ the humor is phisycal or non verbal (Berger dalam Anastasya, 2013: 5-7) akan digunakan untuk melihat konsep humor Ketoprak Tjonthong. Adapun penjelasannya ke empat kategori tersebut adalah sebagai berikut.

\section{Kategori A (Language / The humor is verbal)}

1. Bombast: bicara muluk

2. Infantilism: bermain dengan bunyi/kata-kata

3. Irony:menyatakan makna kebalikan dari makna sebenarnya

4. Missunderstanding: salah menafsirkan situasi

5. Pun: permainan makna kata
6. Repartee: mengolok secara verbal

7. Ridicule: membuat orang terlihat bodoh verbal dan non verbal

8. Sarcams: nada tajam

9. Satire: mempermalukan suatu hal, tokoh, dll

10. Sexual allusion: Menyindir dengan nakal/seksual

11. Outwitting: Mengalahkan dengan melontarkan pertanyaan atas pernyataan

\section{Kategori B (The humor is ideational)}

1. Irreverent behavior: tidak menghormati standard yang berlaku.

2. Malicious pleasure: menertawakan kemalangan orang lain

3. Absurdity: omong kosong, situasi tidak logis

4. Coincidence: kejadian kebetulan dan tak terduga

5. Conceptual surprise: mengelabuhi dengan perubahan konsep yang tak terduga

6. Dissapointment: situasi mengarah kekecewaan

7. Ignorance: naïf, lug, kekanak-kanakan

8. Repetition: pengulangan dari situasi yang sama

9. Ridigity: Seseorang yang berfikir konservatif dan tidak fleksibel

\section{Kategori C (Identity/the humor is} existensial)

1. Anthropomorphism: benda/binatang berciri manusia

2. Eccentricity: sebuah karakter aneh/menyimpang dari norma

3. Embarrassment: Situasi canggung, gelisah, malu

4. Grotesque appeareance: penampakan aneh, mengerikan

5. Imitation: meniru 
6. Impersonation: mengambil identitas orang lain

7. Parody: meniru gaya/genre

8. Scale: objek berukuran sangat besar/kecil

9. Stereotype:Steriotip/ generalisasi

10. Transformation: mengalami metamorfosa/ mengambil bentuk orang lain

11. Visual surprise: perubahan fisik yang tak terduga

\section{Kategori D (Action/ the humor is phisycal} or non verbal)

1. Clownish behavior: membuat gerakan yang kuat menggunakan kaki

2. Clumsiness: sikap canggung/ kikuk/kaku

3. Chase:mengejar seseorang/ sesuatu

4. Exaggeration: bereaksi dengan cara melebih-lebihkan

5. Peculiarface: ekspresi wajah lucu/ meringisPeculiar music: musik yang tidak biasa

6. Peculiar sound: bunyi tidak biasa seperti di kartun

7. Peculiar voice: suara lucu

8. Slapstik: lelucon yang kasar secara fisik

9. Speed: berbicara atau bergerak dengan sangat cepat/ lambat

Pola dan ideologi Ketoprak Tjonthong akan dideskripsikan dengan menggunakan pendekatan struktural. Struktur dalam konteks penelitian ini adalah unsur-unsur atau komponen-komponen yang tersusun menjadi satu kerangka bangunan yang berupa tempat, hubungan, atau fungsifungsi dari adegan-adegan di dalam peristiwa-peristiwa dan di dalam satu keseluruhan lakon (Levitt dalam Sudiro Satoto, 2012: 38).

\section{Metode dan Data}

Untuk menemukan jawaban tentang konsep humor dalam ketoprak Tjonthong maka dipilih satu lakon untuk dijadikan studi kasus. Lakon yang dipilih berjudul Panguwasa Samodra (2019). Secara operasional kajian ini melalui dua tahap yaitu tahap pengumpulan data dan tahap analisis data. Pengumpulan data meliputi studi kepustakan dan bedah naskah. Studi kepustakaan dilakukan untuk mencari sumber literer yang berkaitan dengan teori humor yang digunakan sebagai alat untuk mengkaji lakon Panguwasa Samodra. Analisis data dilakukan dengan melacak peristiwa yang terjadi pada setiap adegan dari 2 lakon tersebut. Selanjutnya mengklasifikas i konsep humor yang terdapat dalam lakon tersebut untuk dianalisis menggunakan teori humor dari Arthur Berger. Langkah selanjutnya adalah mencari pola-pola penempatan humor yang terdapat dalam ke 2 lakon tersebut, serta menemukan alasanalasan yang mendasari pemilihan bentuk tersebut. Untuk memperkaya hasil kajian berkaitan dengan pola dan ideologi Ketoprak Tjonthong juga diamati dua lakon lain berjudul Baron Sakendher (2018) dan Keris Mataram (pentas daring 2020).

\section{Hasil dan Pembahasan}

Sebagaimana telah disebutkan di atas, untuk melihat humor dalam lakon Panguwasa Samodra digunakan teori humor Arthur Berger yang terdiri dari 41 konsep humor. Berdasarkan hasil kajian yang telah dilakukan, tidak semuanya dapat ditemukan dalam lakon Panguwasa Samodra. Oleh karena itu, untuk menjelaskan jenis-jenis humor yang terdapat dalam lakon ini, akan dibahas secara berurutan adegan per adegan. 


\section{Konsep Humor Lakon Panguwasa Samodra}

Sebelum membahas humor, akan disampaikan tentang struktur pengadeganan lakon Panguwasa Samodra. Secara umum, struktur pertunjukan ketoprak yang dianggap baku terbagi menjadi tujuh bagian, yaitu adegan kraton/kadipaten, adegan taman, adegan kesatriyan, adegan padhepokan, adegan pedesaan, adegan alun-alun dan straat (jalanan) (Kayam dkk, 2000: 353). Struktur Pengadeganan lakon Panguwasa Samodra terdiri dari tujuh adegan. Adeganadegan tersebut yaitu: 1). adegan jalan, 2). adegan rumah, 3). adegan bukit Danaraja, 4). adegan keraton Kalinyamat, 5). adegan keraton Pajang, 6). adegan laut, dan 7). adegan keraton Kalinyamat. Jika diamati, maka struktur pengadeganan lakon Panguwasa Samodra masih mengacu pada struktur pertunjukan ketoprak secara umum, meski terdapat sedikit perbedaan. Dari tujuh adegan terdapat lima adegan yang mengandung unsur humor yakni adegan 2, 3, 4, 5, dan 6. Jika dirinci lagi, dari ke 5 adegan tersebut, terdapat 2 adegan yang banyak mengandung konsep humor yaitu adegan 2 dan 4.

Adegan 2 lakon Panguwasa Samodra merupakan adegan yang paling didominasi konsep humor. Hampir semua kategori humor bersifat verbal terdapat di dalamnya seperti bombast, irony, misunderstanding, pun, repartee, sarcasm, dan sexual allusion. Hal menarik dari lakon ini adalah bahwa dalam satu peristiwa, beberapa konsep humor dapat terjadi secara bersamaan dan bergantian.

Adegan 2 diawali dengan peristiwa pertengkaran sepasang pengantin baru (Sandi Asma dan Nyi Sakarin) yang baru saja melangsungkan pernikahan. Nyi Sakarin marah karena baru seminggu menikah sudah akan ditinggal suaminya bertugas sebagai prajurit sandi. Karena emosi Nyi Sakarin melemparkan berbagai peralatan dapur seperti dandang, ceret, baskom sebagai bentuk protes kepada suaminya. Walaupun bertengkar, suasana yang terbangun bukan tegang namun justru lucu.

Secara bombast (bicara muluk) Nyi Sakarin curhat tentang pengorbanan yang telah dilakukan untuk menikah dengan Sandi Asma. Pengorbanan tersebut berupa pengorbanan batin dan juga pengorbanan materi yang semua itu tidak sebanding dengan hasil yang didapat setelah menikah. Sementara Sandi Asma lebih banyak memunculkan humor irony, dimana kata-kata yang diucapkan tidak sesuai dengan kenyataan sebenarnya. Sandi Asma merasa bangga memiliki istri yang terampil, pandai mencari uang, masih muda, dan cantik. Walaupun istrinya terampil dan pandai mencari uang, tetapi kenyataanya umurnya lebih tua 20 tahun dan tidak cantik. Hal ini membuat Nyi Sakarin sangat khawatir Sandi Asma akan meninggalkan dirinya jika bertemu banyak wanita muda di luar rumah. Saking posesifnya, melahirkan situasi yang tidak logis (absurd) saat dia minta suaminya berhenti dari pekerjaannya sebagai prajurit sandi dan tinggal di rumah. Nyi Sakarin yang akan bekerja mencari rejeki sedangkan Sandi Asma cukup di rumah mengerjakan urusan dapur, sumur, dan kasur (olah-olah, asahasah, umbah-umbah lan mlumah). Sebuah pertukaran posisi yang dalam konsep masyarakat Jawa tabu untuk dilakukan, namun menjadi lumrah dalam konteks humor.

Humor missunderstanding (salah menafsirkan situasi) muncul dalam pembicaraan yang dilakukan oleh Sandi Asma dan Sandi karya saat membahas tugasnya sebagai prajurit telik sandi yang harus menjaga Retna Kencana. Ritual tapa wuda yang dijalani Retna Kencana ditafsir dengan sangat berbeda dari kenyataan yang terjadi. Sandi Karya memaknai tapa wuda dari kata tapa yang berarti nulungi (menolong) wuda berarti ben diinjen, jadi 
tapa wuda bermakna membantu orang-orang yang suka mengintip, memberi kesempatan bagi yang ingin mengintip. Penafsiran situasi yang lucu dan mengada-ada. Salah tafsir terhadap ritual tapa wuda yang dilakukan oleh Retna Kencana ternyata tidak hanya terjadi pada Sandi Asma dan Sandi Karya. Bahkan tokoh sebesar Hadiwijaya (Adipati Pajang) juga memiliki persepsi yang sama tentang tapa wuda yang dilakukan Retna Kencana (Adegan 3).

Konsep humor yang muncul secara bersamaan berupa sarkas (kata-kata tajam) dibarengi dengan slapstick (gerakan fisik yang kasar) ketika Nyi Sakarin melempar perabotan rumah ke arah Sandi Asma dan Sandi Karya kemudian muncul membawa bendho (parang) dan berkata: "wani mangkat, mati!!!". Sandi Karya mencoba menengahi pertikaian antara Sandi Asma dan Nyi Sakarin. Namun sayang, bukan menyelesaikan masalah justru semakin memperkeruh suasana karena secara sengaja dia melakukan repartee (mengolok-olok) kepada Nyi Sakarin.

Terjadi kejar-kejaran (chase) antara Nyi Sakarin dan Sandi Asma. Sandi Asma yang ketakutan berlindung di balik tubuh Sandi Karya. Panji Lanang, lurah prajurit sandi yang bermaksud melerai tak kuasa menghadapi amarah Nyi Sakarin. Panji Lanang mengambil tiga buah tombak. Panji Lanang memegang satu tombak, sedangkan ke dua tombak lainnya dilemparkan ke arah Sandi Asma dan Sandi Karya. Ketiga prajurit sandi masing-masing memegang satu tombak dan langsung mengarahkan tombaknya pada Nyi Sakarin hingga membuatnya menjadi ketakutan.

Peristiwa selanjutnya adalah humor yang bersifat naïf dan kekanak-kanakan (ignorance) dimana mereka secara bersamaan meletakkan tombak atau parangnya. Pada saat Panji Lanang, Sandi Asma dan Sandi Karya mengambil tombaknya secara bersamaan, saat itu pula
Nyi Sakarin mengambil parang. Ketika mereka meletakkan tombak di tanah, Nyi sakarin juga melakukan hal yang sama. Adegan ini terasa sangat lucu karena terjadi pengulangan dari situasi yang sama (repetition) secara berulang kali. Kelucuan semakin terasa ketika dilanjutkan humor permainan makna kata (pun). Baik Panji Lanang maupun Nyi Sakarin tidak pernah merasa takut dengan senjata yang dipegang oleh mereka masing-masing. Mereka sangat tahu bahwa kedua senjata itu baik tombak maupun parang hanyalah senjata mainan, tidak tajam, dan terbuat dari kayu.

Humor repetition berupa pelemparan perabot rumah tangga juga terulang lagi pada akhir adegan 2. Jika di awal adegan yang melemparkan perabot dapur adalah Nyi Sakarin, maka di akhir adegan 2 yang melemparkan perabot dapur adalah Sandi Asma. Hal ini dipicu oleh peristiwa Nyi Sakarin yang akan dititipkan di Rumah Demang Laksamana merasa takut untuk tidur sendiri. Oleh karena itu, selama ditinggal suaminya bertugas Nyi Sakarin minta kepada $\mathrm{Ki}$ Demang untuk menemani tidur. Mendengar pembicaraan tersebut Sandi Asma marah dan melempari Nyi Sakarin dengan perabot rumah tangga.

Adegan 3 menceritakan tentang pertemuan antara Retna Kencana dan Adipati Pajang Pangeran Hadiwijaya di Bukit Danaraja. Hadiwijaya bermaksud menemui Retna Kencana untuk membicarakan tentang strategi mengalahkan Harya Penangsang. Peristiwa pertemuan yang terjadi antara Hadiwijaya dan Retna Kencana melahirkan humor yang berupa verbal dan non verbal. Pada pertemuan tersebut Hadiwijaya tampak dalam situasi malu (embarrassment) sehingga sikapnya menjadi canggung dan kikuk (clumsiness). Hadiwijaya selalu membalikkan badan dan tidak mau bertatap muka langsung karena mengira Retna Kencana betul-betul wuda (tanpa busana). 
Suasana lucu kembali hadir dengan kemunculan tokoh Semangkin (keponakan Retna Kencana). Hadiwijaya jatuh hati dengan kecantikan, kecerdasan, dan sifat Semangkin yang ceplas-ceplos. Di sini penulis naskah merangkai kejadian yang berupa peniruan (imitasi). Hadiwijaya meniru tindakan dan kata-kata yang disampaikan oleh Semangkin berkaitan dengan saudara kembarnya yang tidak dimunculkan di panggung dengan alasan "agar tidak menambah jumlah pemain". Hadiwijaya juga melakukan hal yang sama saat menjawab pertanyaan Semangkin tentang keberadaan para abdi yang mendampinginya.

Panji Lanang, Sandi Karya, dan Sandi Asma akan pergi menunaikan tugas. Nyi Sakarin menangisi kepergian suaminya. Sandi Asma mencoba membujuk dan menenangkan istrinya. Perpisahan yang seharusnya sedih, malah menjadi humor karena dialog kedua tokoh tersebut adalah syair lagu Banyu Langit ciptaan Alm. Didi Kempot. Peristiwa selanjutnya adalah perpisahan antara Sandi Asma dan Nyi Sakarin. Saat Sandi Asma hendak memeluk istrinya, Sandi Karya datang mengajak segera pergi. Nyi Sakarin marah dan mengusir Sandi Karya. Nyi Sakarin dengan berlebih-lebihan (exaggeration) minta untuk dicium sebagai tanda cinta. Humor situasi terjadi ketika Sandi Asma mengajak Nyi Sakarin mojok di tempat yang tersembunyi agar tidak diintip Sandi Karya. Belum sempat memenuhi keinginan istrinya, Sandi Asma sudah ditarik Panji Lanang untuk dibawa pergi. Namun lagi-lagi Sandi Asma berontak dan melepaskan tangannya, lalu berlari menggandeng tangan istrinya keluar panggung. Tak lama kemudian Sandi Asma muncul lagi sambil membetulkan bajunya dan mengajak Panji Lanang segera pergi.

Humor dalam adegan ini terjadi saat Patih Sungging Badar Dhuwung (Tjie Hwio Gwan) dan Hadiwijaya sedang membicarakan tentang kehebatan Senopati perang perempuan bernama Tumenggung Rara Meladi. Sungging Badar Dhuwung adalah seorang duda yang sedang membutuhkan seorang istri untuk menjadi pendamping hidupnya. Ia bermaksud melamar Tumenggung Rara Meladi yang terampil dan mempuni dalam segala hal untuk melayani dirinya. Sungging Badar Dhuwung mengaku sebagai lelananging jagad, lancuring bawana. Rara Meladi menolak lamaran tersebut dan menganggapnya sebagai laki-laki tua yang tidak tahu diri, sudah bau tanah, belum sempat berbuat apa-apa sudah keburu mati. Sebagai pejantan Tangguh, Sungging Badar Dhuwung tidak terima dengan hinaan dari Rara Meladi dan menantang untuk membuktikan hal tersebut. Disinilah, penulis naskah menggunakan konsep humor sexual allusion (menyindir dengan nakal) untuk menciptakan humor dalam adegan 5. Selain itu, penulis naskah juga memunculkan sisi absurd tokoh Sungging Bandar Dhuwung. Patih Sungging Bandar Dhuwung yang seharusnya menjadi orang pertama maju ke medan perang, justru menjadi seksi konsumsi yang tugasnya menyediakan makan untuk para prajurit.

Konsep humor conceptual surprise yakni mengelabui dengan konsep yang tak terduga digunakan oleh penulis naskah untuk memunculkan humor di adegan 6. Soreng Rana dan Soreng Pati dua orang perusuh berasal dari Jipang sedang menyamar sebagai rakyat biasa untuk mengelabui mangsanya. Soreng Pati berpura-pura sebagai bapak yang sedang sakit keras, dan Soreng Rana menjadi anaknya. Mereka bertemu dengan Tumengung Samirana yang juga sedang menyamar sebagai pedagang. Hal tak terduga muncul saat Soreng Rana secara dramatis mengarang cerita tentang bapaknya yang sakit akibat kualat kepada dirinya. Bagi logika umum tidak masuk akal jika ada orang tua kualat kepada anaknya, namun melalui 
Soreng Rana penulis naskah berusaha menjelaskan fenomena tersebut menjadi nalar. Sejak kecil bapaknya sangat nakal. Kakeknya menjadi korban kenakalannya karena didorong ke sumur, sakit, dan akhirnya meninggal dunia. Ketika besar, ayahnya menikah dengan ibunya hingga lahirlah Soreng Rana. Ternyata, ibunya sangat menderita karena sering mendapatkan KDRT dari bapaknya. Akhirnya Soreng Rana menjadi anak piatu. Kemudian bapaknya memutuskan untuk menikah lagi dengan gadis desa bernama Winih yang tak lain adalah kekasih dari Soreng Rana anaknya sendiri. Pernikahan tersebut terpaksa dilakukan karena Pak Trubus (bapaknya Winih) terlilit hutang. Ayah Soreng Rana bersedia membayar semua hutang tersebut asal Winih bersedia menjadi istrinya. Pernikahan terjadi secara kilat, esuk ijab, awan minggat, let setahun mulih njaluk pegat. Setelah menjadi janda, Winih menemui Soreng Rana dan mengajaknya untuk menikah. Soreng Rana menolak dengan alasan tidak mungkin menikah dengan ibu tiri mantan istri bapaknya. Winih tidak kekurangan akal, dia kemudian menikahi Raceng, seorang laki-laki yang bertingkah seperti perempuan. Raceng juga mendapat julukan Joko Arum karena kemana-mana selalu memakai parfum dan memakai bedak. Pernikahan kilat itupun berakhir sudah. Setelah bercerai dengan Raceng, Soreng Rana bersedia menikah dengan Winih. Soreng Rana mau menikah dengan alasan Winih bukan lagi mantan ibu tirinya, namun dia sudah menjadi jandanya Raceng sehingga dia tidak merasa berdosa. Sakit yang diderita bapaknya adalah karma yang harus dijalani akibat perbuatan yang dilakukan bapaknya kepada dirinya di masa lalu.

Permainan makna kata (pun) terlihat dalam pemberian nama tokoh yang dipakai oleh Soreng Rana untuk mengelabui Tumenggung Samirana. Soreng Rana mengaku terlahir sebagai anak kembar tiga bernama Radi Rana (dia sendiri), Radi Riki (perempuan), dan Radi Tebih (meninggal). Nama-nama tersebut dalam bahasa Jawa berarti sedikit kesana, sedikit kesini, dan sedikit jauh.

\section{Pola Humor Ketoprak Tjonthong}

Menurut hasil pengamatan yang telah dilakukan, Ketoprak Tjonthong menggunakan tiga pola dalam membangun unsur humor. Ketiga pola tersebut adalah pola pengkarakteran pemain, pola penamaan tokoh, dan pola pengadegan. Di bawah ini akan diuraikan satu persatu ketiga pola tersebut.

\section{a. Pola pengkarakteran pemain}

Diketahui bahwa pengkarakteran
pemain dalam pertunjukan ketoprak
menggunakan sistem stereotype, yaitu masing-masing pemeran/aktor sudah memiliki karakteristik penokohan tokoh tertentu. Sebagai informasi, saat ini grup Ketoprak Tjonthong memiliki 11 pemain tetap, yaitu Susilo Nugroho, Marwoto, Bagong Sutris Gunanto, Nano Asmorondono, Rini Widyastuti, Hargi sundari, Ngatirah, Wisben Antoro, Novi Kalur, Rio Srundeng, dan Bayu Saptama. Dalam setiap penampilannya juga dibantu oleh beberapa pemain insidentil dan penari. Berkaitan dengan ilustrasi musik, mulai awal berdiri hingga saat ini selalu digarap oleh Warsana dibantu para pemusik yang lain.

Berdasarkan pengamatan yang dilakukan pada Lakon Panguwasa Samodra, pola pengkarakteran pemain sangat diperhatikan agar suasana humor dapat terbangun secara maksimal. Pembagian karakter pemain dibedakan menjadi kelompok-kelompok. Kelompok dagelan tua, Marwoto (Sungging Badar Duwung) disandingkan dengan Susilo Nugroho (Panji Lanang). Sedangkan kelompok dagelan muda, yaitu Rio Srundeng (Sandi Asma) 
disandingkan dengan Wisben (Sandi Karya) bertemu dengan Novi Kalur (Soreng Rana). Sementara pemain-pemain lain adalah pendukung terjadinya humor, seperti Ngatirah (Nyi Sakarin), Hargi sundari (Tumenggung Rara Meladi), Nano Asmarandana (Soreng Pati), dan lain-lain.

Pola ini juga terdapat dalam lakon Baron Sakendher (2018), dimana Marwoto berperan sebagai Baron Kawitparu selalu didampingi Susilo Nugroho yang berperan sebagai Samas (abdi setia dari Baron Kawitpatru). Novi dan Rio yang merupakan pasangan dagelan muda berperan sebagai Kukup dan Krakal yang merupakan prajurit dari Nusa Tembini dipasangkan dengan Wisben yang berperan sebagai Raja Spanyol. Dalam lakon ini kelucuan juga terjadi ketika Ngatirah yang berperan sebagai Mbok Untali bertemu dengan Marwoto (Baron Kawitparu).

Pola yang sama juga dapat dilihat dari pementasan daring (2020) dengan lakon Keris Mataram. Marwoto (Wahyu) berpasangan dengan Susilo Nugroho (Indra), sementara Rio dan Novi dipasangkan dengan Heru Saptama, dimana ketiganya berperan sebagai perampok. Dalam lakon ini, lagi-lagi kelucuan terjadi ketika Ngatirah (Abdi dari Nyai Senapati Harga Sundara) dipertemukan dengan Marwoto (Wahyu).

\section{b. Pola penamaan tokoh}

Penamaan tokoh dalam lakon-lakon Ketoprak Tjonthong merupakan gabungan dari dua unsur yaitu fakta dan fiksi. Sebagaimana diketahui bahwa lakon-lakon ketoprak biasanya diangkat dari babad, legenda, dan cerita sejarah. Berkaitan dengan lakon-lakon Ketoprak Tjonthong, dalam proses penciptaannya Susilo Nugroho juga melakukan studi literatur.

Lakon Panguwasa Samodra merupakan cerita yang diangkat dari latar belakang sejarah Babad Tanah Jawa di masa Kerajaan Pajang menuju Mataram Islam.
Lakon ini menceritakan perjuangan Ratu Kalinyamat yang bercita-cita menguasai samodra agar dapat berguna bagi semua bangsa di Nusantara. Dalam lakon ini, beberapa nama tokoh sejarah seperti Ratu Kalinyamat, Pangeran Hadiri, Hadiwijaya, Danang Sutawijaya, Sungging Badar Duwung, maupun beberapa tokoh lain tidak mengalami perubahan karena masih mengacu pada sejarah dan babad. Namun, untuk beberapa tokoh fiktif, pemberian nama mengandung maksud tertentu dan berkonotasi lucu seperti Sakarin (gula pasir palsu), Samirana (nama sebuah daerah di Yogyakarta), Radi Rana, Radi Riki, dan Radi Tebih. Sandi Asma dan Sandi Karya untuk dua nama prajurit sandi.

Pola penamaan tokoh dalam konteks humor juga terlihat dalam lakon Baron Sakendher yang dipentaskan tanggal 7-8 September 2018 di Concert Hall Taman Budaya Yogyakarta. Baron Sakendher menceritakan kehidupan Sakendher dari lahir, meninggalkan Spanyol hingga menetap di Mataram. Penamaan tokoh dalam lakon ini juga gabungan dari asli dan rekaan. Untuk tokoh-tokoh utama seperti Baron Kawitparu, Ken Manikhara, Baron Sakendher, Resi Mintuna, Retna Sayempraba, dan beberapa nama lain masih tetap mengacu pada legenda yang sudah ada. Namun, untuk beberapa tokoh tambahan, pemberian nama mengandung unsur humor seperti nama beberapa teman Baron yakni Samas, Kukup, Krakal yang identik dengan nama pantai di daerah Gunung Kidul. Di samping itu, beberapa penari juga diberi nama Julio, Augusto, Septembero, Syawalo, dan dulkangidaho agar kelihatan berbau Spanyol. Untuk nama emban yang ikut menjilat pelog (isi manga) hingga hamil bernama Mbok Untali.

c. Pola pengadegan

Secara umum pola pengadegan Ketoprak Tjonthong masih mengacu pada 
pola pengadegan ketoprak konvensional meski menggunakan format ketoprak garapan. Ketoprak garapan adalah ketoprak yang digarap dengan memadukan idiomidiom kesenian lain sehingga penyajian unsur-unsurnya tampak lebih tergarap (Nusantara, 1997: 55). Adapun ciri dari bentuk ketoprak garapan adalah sebagai berikut.

1) Menggunakan naskah penuh (full play)

2) Tangga dramatik mengacu pada dramaturgi barat

3) Akting dan bloking ditata atau terpola

4) Tata rias dan busana realis, simbolis

5) Setting tidak harus memakai kelir (layar bergambar)

6) Tata lampu dan suara memanfaatkan teknologi elektro

7) Instrumen pengiring bebas (diatonis, pentatonis, kombinasi keduanya)

8) Lama pertunjukan kurang lebih 2,5 jam

9) Keprak kadang dipakai, kadang tidak

10) Tembang kadang dipakai, kadang tidak (Nusantara, 1997: 55)

Terkait dengan humor dalam pola pengadegan ketoprak Tjonthong, unsur humor ditempatkan pada peristiwa dengan setting tempat yang lebih bebas (rumah, jalan, bukit, laut). Berdasarkan hasil pengamatan yang telah dilakukan dari 7 adegan yang terdapat dalam lakon Panguwasa Samodra, unsur humor dimunculkan di adegan 2,3,4,5, dan 6 . Adegan tersebut berlatar tempat rumah, jalan, bukit, dan laut. Kalaupun terdapat sedikit unsur humor dalam adegan kraton, peristiwa itu terjadi setelah raja dan patih keluar.

Pola pengadegan lakon Baron Sakendher memiliki kemiripan dengan lakon Panguwasa Samodra. Dari tujuh adegan yang diamati dalam lakon tersebut, adegan humor muncul pada adegan 1, 2,3,4,5 dan 6 yang berlatar rumah, padepokan, telatah Nusa Tembini dan istana Spanyol. Adegan humor banyak muncul di istana Spanyol, namun tidak dengan adegan Keraton Mataram (adegan 7). Mungkinkah karena Spanyol tidak di Jawa, tak terikat oleh norma dan etika Jawa, hingga rajapun bebas untuk dibully dan dijadikan guyonan. Berbeda dengan adegan Keraton Mataram yang masih menempatkan Panembahan Senapati sebagai raja yang berwibawa dan dihormati. Sepertinya Ketoprak Tjonthong masih berhati-hati menempatkan unsur humor di adegan keraton (Intarti, 2020:36).

Temuan lain terkait pola pengadegan yaitu pada satu peristiwa terdapat unsur humor yang tersusun dari rangkaian beberapa konsep. Biasanya berupa verbal berbarengan atau dilanjutkan gerak fisik dan ekspresi. Sebagai contoh dalam lakon Panguwasa Samodra, saat humor sarkas (kata-kata tajam) muncul berbarengan dengan slapstick (gerakan fisik yang kasar) diwujudkan dalam peristiwa Nyi Sakarin melempar perabotan rumah ke arah Sandi Asma dan Sandi Karya kemudian muncul membawa bendho (parang) dan berkata: "wani mangkat, mati!!!”. Sandi Karya yang mencoba menengahi pertikaian tersebut malah semakin membuat Nyi Sakarin marah karena secara sengaja dia mengolok-olok (repartee) dengan kata-kata tua, elek, kupinge bosok.

\section{c. Ideologi Humor Ke toprak Tjonthong}

Ketoprak Tjonthong
memiliki
tampilan yang berbeda dari
konvensional. Format garap ketoprak
Tjonthong mengacu pada ketoprak garapan
yang memasukkan unsur teater modern
dalam pemeranan, tata panggung, tata cahaya
maupun garap musiknya. Sebagai sajian
ketoprak garap baru yang berupaya
menciptakan sajian yang dinamis dan
komunikatif, grup ini meramu tiga unsur
yakni problem-problem sosial di masyarakat,
cerita-cerita baru yang belum pernah
dipentaskan, dan unsur humor dalam setiap
lakon yang dibawakan.

Melalui humor satir, grup ini mengangkat isu-isu sosial dalam masyarakat 
dengan enteng. Persoalan kemanusiaan, kekerasan, politik kekuasaan dan lainnya diramu dengan kreatifitas seni menjadi sajian yang ringan namun kritis. Tanpa meninggalkan fungsi ketoprak Tjonthong sebagai hiburan bagi masyarakat.

Lakon-lakon dalam pertunjukan ketoprak Tjonthong selalu mengambil sumber pada serat, babab, dan cerita tutur lain yang digarap dengan konten ala Ketoprak Tjonthong. Ciri khas grup ini selalu berusaha memanggungkan lakon yang jarang atau bahkan belum pernah dipentaskan oleh grup ketoprak lain. Contoh beberapa lakon yang pernah dipentaskan Ketoprak Tjonthong namun kurang familier bagi pandemen ketoprak yaitu: Putri Cina, Baron Sakendher, Sang Presiden, Walidarma, Keris Mataram dan masih banyak lagi. Gagasan untuk selalu mementaskan lakon-lakon baru tampak pada atur panuwun yang disampaikan oleh Susilo Nugroho (penulis naskah) dalam naskah lakon Walidarma yang ditulis tahun 2019.

"Sak pangertiku crita kang kamot ing buku mau durung tau dikhetoprake. Mula dadi tambah mantep anggone kepengin gawe naskah ketoprak. Muga-muga pepenginanku ora mung mandheg ing angen-angen, nanging disengkuyung kabeh kanca bisa dadi pementasan sing apik, unik, berbobot ning ya lucu tur durung tau ana sing gawe pementasane" (hal.2).

Pernyataan di atas menyiratkan bahwa ketoprak Tjonthong dalam pertunjukannya selalu mengedepankan originalitas karya, dikemas dalam sajian yang unik, bagus, di samping sangat mempertimbangkan unsur humor.

\section{SIMPULAN}

Ketoprak Tjonthong dari Yogyakarta merupakan grup ketoprak yang menggunakan humor sebagai identitas pertunjukannya. Idiom humor dipilih agar tema dan pesan tentang fenomena sosial yang dibahas dalam pertunjukan sampai kepada penonton dengan penyampaian yang lucu, menyenangkan dan menghibur.

Penggunaan konsep humor dalam lakon Panguwasa Samodra dapat dilihat pada hampir semua adegan. Dari tujuh adegan yang terdapat di lakon tersebut, lima di antaranya banyak mengandung konsep humor yaitu adegan 2, 3, 4, 5, dan 6. Dari ke 41 konsep humor yang dicetuskan oleh Arthur Berger terdapat enambelas konsep humor yang dapat ditemukan dalam lakon Panguwasa Samodra. Di antaranya bombast, irony, misunderstanding, pun, repartee, sarcasm, dan sexual allusion yang berkaitan dengan verbal. Konsep conceptual surprise, absurd, repetition dan ignorance sebagai implementasi humor sebagai hasil pemikiran juga dapat ditemukan di lakon tersebut. Di samping itu, juga dapat ditemukan konsep embarrassment dan imitation dalam konteks humor sebagai identitas diri. Berkaitan dengan tindakan fisik yang berupa gerak dan ekspresi beberapa konsep humor yang dapat ditemukan adalah clumsiness, chase, dan exaggeration.

Dari 3 lakon yang diamati yaitu lakon Panguwasa Samodra, Lakon Baron Sakendher, dan lakon Keris Mataram, pola humor Ketoprak Tjonthong terimplementasi dalam tiga hal yaitu pola pengkarakteran pemain, pola penamaan tokoh, dan pola pengadegan. Adapun ciri khas dari Ketoprak Tjonthong yang menjadi ide dasar pementasannya adalah selalu mengangkat problematika sosial masyarakat, dengan menggunakan lakon-lakon yang baru/belum dikenal, dan dalam balutan humor yang segar.

\section{Daftar Pustaka}

Anastasya, Sicilia. 2013. "Konsep-Konsep Humor dalam Program Komedi di Televisi Swasta Nasional Indonesia" dalam E-Komunikasi jurnal program Studi Ilmu Komunikasi volume 1 nomor 
1, P. 1-11. Surabaya: Universitas Kristen Petra.

Intarti, Retno Dwi. 2020. "Humor Dalam Ketoprak Tjonthong: Konsep, Pola, dan Ideologinya" Laporan Penelitian Dosen Mandiri Lembaga Penelitian ISI Yogyakarta.

Kayam, Umar, dkk. 2000. "Pertunjukan

Rakyat Tradisional Jawa dan Perubahan" dalam Heddy Shri Ahimsa Putra, ed. Ketika Orang Jawa Nyeni. Yogyakarta: Galang Press.

Maulana, Alif. 2016. 'Kethoprak Conthong Yogyakarta dalam Lakon Lampor Kajian Bentuk dan Fungsi Pertunjukan" Skripsi untuk memenuhi persyaratan S-1 pada Program Studi Jurusan Teater Fakultas Seni Pertunjukan ISI Yogyakarta.

Nugroho, Susilo. 2019. "Walidrama" (Naskah Lakon). Yogyakarta: t.p.

Nugroho, Susilo. 2019. "Panguwasa Samodra” (Naskah Lakon). Yogyakarta: t.p.

Nugroho, Susilo. 2018. "Baron Sakendher" (Naskah Lakon). Yogyakarta: t.p.

Rahmanadji, Didik. 2007. "Sejarah, Teori, Jenis, dan Fungsi Humor" dalam Bahasa dan Seni jurnal Fakultas Sastra tahun 35 no 2, p.215-221. Jakarta: UM.
Setyawan, Bagus Wahyu dan Kundharu Saddono. 2019. "Akulturasi Budaya Islam-Jawa dalam Pementasan Kesenian Ketoprak" dalam Dance \& Theater Review jurnal tari, teater, dan wayang volume 2 nomor 1, p. 25-34. Yogyakarta: Fakultas Seni Pertunjukan ISI Yogyakarta.

Satoto, Sudiro. 2012. Analisis Drama \& Teater. Yogyakarta: Penerbit Ombak.

Soemanto, Subakdi. 1997." Ketoprak Masa Kini: Kung-fu dan Gerrr?", dalam Lephen Purwaraharja dan Bondan Nusantara, ed. Ketoprak Orde Baru.

Yudiaryani, Wahid Nurcahyono, dan Silvia Anggreni Purba. 2019. "Strategi Penguatan Kreativitas Seniman Ketoprak DIY tahun 1999 hingga tahun 2009" dalam Dance \& Theater Review jurnal tari, teater, dan wayang volume 2 nomor 2, p. 94-105. Yogyakarta: Fakultas Seni Pertunjukan ISI Yogyakarta. 